\title{
Clinical Practice for Novice Nursing Students: Shorter Clinical Day or Longer Clinical Day?
}

\author{
Kobayashi Akiko*, Penny Bacon \\ Department of Nursing, Biola University, 13800 Biola Avenue, La Mirada, California 90639, USA
}

Article Details
Article Type: Research Article
Received date: $30^{\text {th }}$ March, 2019
Accepted date: $04^{\text {th }}$ June, 2019
Published date: $04^{\text {th }}$ September, 2019
"Corresponding Author: Kobayashi Akiko, Department of Nursing, Biola University, 13800 Biola Avenue, La Mirada, Cal-
ifornia 90639, USA. E-mail: akiko.kobayashi@biola.edu
Citation: Kobayashi A, Bacon P (2019) Clinical Practice for Novice Nursing Students: Shorter Clinical Day or Longer Clin-
ical Day?. J Comp Nurs Res Care 4: 141. doi: https://doi.org/10.33790/jcnrc1100141.
Copyright: C2019, This is an open-access article distributed under the terms of the Creative Commons Attribution License
4.0, which permits unrestricted use, distribution, and reproduction in any medium, provided the original author and source are
credited.

\begin{abstract}
Background: Clinical education is an essential component of nursing curricula. The number of studies on novice nursing students'(NSs) exposure and acquisition of nursing skills is limited. The present study primarily aimed to compare the frequency of skills performance of NSs assigned to short and long clinical days for the first clinical rotation. This study is unique, as NSs had a mixed experience of short and long clinical days within one semester.

Methods: 40 first-clinical semester NSs were randomly divided into four clinical groups. The study compared the mean number of skills performed by NSs s in a 5.5-hour clinical day versus an 8-hour day. NSs were then asked to describe perceived benefits of shorter and longer clinical days at the end of the semester.
\end{abstract}

Results: Findings indicate that longer clinical days provided NSs with more opportunities to practice skills and helped develop better relationships with nursing staff and patients/family members. When two shorter clinical days a week were compared to one longer day, students expressed less anxiety on the second shorter day and less fatigue at the end of a shorter day.

Conclusion: Both shorter and longer clinical days offered unique opportunities for skill acquisition. Introducing NSs to two shorter clinical days per week with the eventual transition to one longer day is recommended during their first clinical rotation.

Key words: Length of clinical days, Novice nursing students, Skill performance, Clinical learning benefits

\section{Introduction}

Pre-licensure nursing programs have a common goal to provide the best learning experiences for their students, and it is important to evaluate the quality of clinical and academic education in nursing programs. One specific aspect of clinical education that guides the learning experience for the first clinical semester nursing students (NSs) is the opportunity to perform nursing skills. The question which drives inquiry of this study is: Does a short or long clinical day provide better learning opportunities for novice NSs? In addition to the duration of the clinical day, the quality of these NSs' clinical experiences depends on various factors, such as opportunity to perform skills, therapeutically communicate with patients [1] and develop relationships with nursing staff [2].
According to the literature, advantages were found in one longer clinical day per week regarding opportunities for skills compared to two shorter clinical days. Tobar et al. [3] found that students were able to enhance their learning experience and participate in shift reports at the end of a longer clinical day [3]. Rossen et al. [4] reported that students were more organized during a 12-hour shift as they were able to provide patient care throughout the day [4]. In addition, Danner [2] stated that students had more time to process patient information and implement appropriate interventions [2]. Gignac et al. [5] found that the longer day gave students the opportunity to increase knowledge regarding medication administration [5]. Longer hours also provided students the opportunity to practice an increased number and variety of skills [6].

Additionally, research has demonstrated that longer clinical days impacted various positive relationships, including nursing staff-tostudent, nursing faculty-to-student, and student-to-patient. Nursing staff preferred that the students experience a 12-hour shift similar to their own shift, thereby promoting continuity of care and student involvement throughout the day [3]. Studies also indicated that students felt more accepted by nursing staff when they worked similar hours $[4,6]$. In addition, clinical instructors were better able to engage and spend more time instructing their students during 12hour clinical shifts, especially in the afternoon hours [2-4]. Lastly, NSs expressed having greater opportunity to provide holistic care by nurturing trust with both the patient and their families throughout a long clinical day [4].

Despite the aforementioned advantages of having one 12-hour shift per week, students also reported numerous disadvantages. Student experiences included the dread of long hours, fear of making errors and the overall constant stress of the clinical environment, which led to higher reported levels of fatigue (8). As a result, student motivation to learn decreased throughout the day due to stress and exhaustion from the prolonged clinical hours [2].

The literature also described undesirable experiences of clinical faculty who worked longer clinical days. Tobar et al. [3] stated that a 12-hour shift required faculty vigilance in patient selections, resulting in clinical instructors experiencing fatigue [3]. At the same time, while attempting to provide opportunities for all students equal to what they would receive in two shorter days, clinical faculty also reported experiencing increased stress [9]. 
For the novice NSs, the length of a clinical day may affect their learning ability because of their high anxiety and stress associated with a new clinical environment and limited knowledge of pathophysiology $[9,10]$. At the same time, students were enthusiastic about administering medications, taking vital signs, and performing physical assessments on real patients; short clinical days might not satisfy these expectations. The appropriate length of a clinical day, especially for novice NSs, needs close evaluation. Overall, there is limited evidence evaluating the effects on novice NSs' learning outcomes in two shorter clinical days as compared to one longer clinical day per week.

In the Bachelor of Science in Nursing (BSN) program at Biola University, La Mirada, California, novice NSs have a unique opportunity to experience both shorter clinical days and longer clinical days during their first clinical rotation. The study was conducted primarily to investigate the differences in the frequency of NSs skills performance between a shorter clinical day and a longer day in one rotation.

\section{Methods}

Forty NSs in the first clinical semester of a BSN program were recruited to participate in the study. The study was approved by the Protection of Human Rights in Research Committee, which is equivalent of Institutional Review Board at Biola University (approved protocol number: F16-010_SE). The NSs completed four semesters of general education required for the BSN program, and are currently being introduced to basic nursing skills and pathophysiology. The expected clinical learning outcomes of the first rotation include demonstrating fundamental nursing skills and developing nursing care plans to provide appropriate patient care.

The nursing students were randomly divided into four groups. Each group consisted of ten NSs and one clinical instructor. The groups were assigned either to a surgical, respiratory, oncology, or neurology unit in one urban community hospital. Each group remained in the same unit throughout the entire rotation. During their first three weeks, the students were scheduled to complete clinical practice for two shorter days per week (6 clinical hours a day, excluding pre- and post-clinical conferences). The students then completed one longer day per week ( 8.5 clinical hours, excluding pre- and post-clinical conferences) for the following five weeks. Two shorter days per week were scheduled on Thursdays and Fridays and one longer day per week was scheduled on Thursdays.

During the post-conference (debriefing) session on every clinical day, students in each clinical group were given a one-page, anonymous questionnaire form (Figure 1). All students participating in the study were instructed to place check marks on the questionnaire form, indicating the skill items they had performed during each clinical day. No identifying information was required of the students at any time. If a student performed one skill twice, the student was instructed to mark twice for the skill. The total number for each skill performed by all 40 students was averaged, and the results were compared between shorter clinical days and longer clinical days. A Student $\mathrm{T}$ test was used to analyze the comparisons of mean numbers of skills performed in short clinical days and long clinical days.

\section{Clinical Learning Opportunities (short day)}

Date: (time ending clinical: 1:00 pm)

Specialty of your floor (circle): Stroke, respiratory, oncology, surgery

\# of students: 10 (or

)

During the post conference, please write " $X$ " for nursing skills that you did below:

\begin{tabular}{|l|l|}
\hline Nursing skills & Did you do this today? \\
\hline Bed bath/general hygiene & \\
\hline Linen change & \\
\hline Passing trays & \\
\hline Oral medication administration & \\
\hline $\begin{array}{l}\text { Subcutaneous or IM } \\
\text { (if twice, mark 2 } \mathrm{x} \text { ) }\end{array}$ & \\
\hline $\begin{array}{l}\text { Insulin administration } \\
\text { (if twice, ,mark 2 } \mathrm{x} \text { ) }\end{array}$ & \\
\hline Acucheck (glucometer) & \\
\hline Assessment (H2T, or focused) & \\
\hline Dressing change observation/assisting & \\
\hline Observing a special procedure & \\
\hline Taking I/O & \\
\hline Patient teaching/ \\
discharge teaching
\end{tabular}

Figure 1. 
Clinical Learning Opportunities (long day)

Date: (time ending clinical: 3:30pm)

Specialty of your floor (circle): Stroke, respiratory, oncology, surgery \# of students: 10 (or

)

During the post conference, please write " $X$ " for nursing skills that you did below:

\begin{tabular}{|c|c|c|}
\hline \multirow[t]{2}{*}{ Nursing skills } & \multicolumn{2}{|c|}{ Did you do this today? } \\
\hline & Before $1 \mathrm{pm}$ & After $1 \mathrm{pm}$ \\
\hline \multicolumn{3}{|l|}{ Bed bath/general hygiene } \\
\hline \multicolumn{3}{|l|}{ Linen change } \\
\hline \multicolumn{3}{|l|}{ Passing trays } \\
\hline \multicolumn{3}{|l|}{ Oral medication administration } \\
\hline \multicolumn{3}{|l|}{$\begin{array}{l}\text { Subcutaneous or IM } \\
\text { (if twice, mark } 2 \text { x) }\end{array}$} \\
\hline \multicolumn{3}{|l|}{$\begin{array}{l}\text { Insulin administration } \\
\text { (if twice, ,mark } 2 \mathrm{x} \text { ) }\end{array}$} \\
\hline \multicolumn{3}{|l|}{ Acucheck (glucometer) } \\
\hline \multicolumn{3}{|l|}{ Assessment (H2T, or focused) } \\
\hline \multicolumn{3}{|l|}{ Dressing change observation/assisting } \\
\hline \multicolumn{3}{|l|}{ Observing a special procedure } \\
\hline \multicolumn{3}{|l|}{ Taking I/O } \\
\hline \multicolumn{3}{|l|}{$\begin{array}{l}\text { Patient teaching/ } \\
\text { discharge teaching }\end{array}$} \\
\hline \multicolumn{3}{|l|}{ Receiving a new admission } \\
\hline & & \\
\hline & & \\
\hline \multicolumn{3}{|l|}{ Skills or procedures unique to your floor: } \\
\hline & & \\
\hline
\end{tabular}

$\mathrm{PB} / \mathrm{AK}$ rev July 27, 2016

\section{Results}

Forty NSs in the first clinical semester participated in the study. Among them, $38 \mathrm{NSs}$ were female and two were male, with the average age of 20.8 years. Table 1 shows the comparisons of the mean frequencies of skills performed by $40 \mathrm{NSs}$ in a shorter clinical day ( 6 hours, excluding pre- and post-clinical conferences) with the ones in a longer clinical day ( 8.5 hours, excluding pre- and postclinical conferences). The mean of a day sum indicates the average frequency of a given skill performed by $40 \mathrm{NSs}$ in one clinical day. As shown in Table 1, significant increases in frequencies were shown in longer days than shorter days in the following skills: glucometer use $(\mathrm{P}=0.014)$, assessing inputs and outputs $(\mathrm{I} / \mathrm{O})(\mathrm{P}=0.015)$, and performing physical assessments $(\mathrm{PA})(\mathrm{P}=0.043)$. These skills were performed more than twice as often in a longer day than in a shorter day: glucometer use went from 13.3 times in a shorter day to 30.8 times on a longer day; PA performance was from 19.3 to 40.2 ; and $\mathrm{I} / \mathrm{O}$ assessment was from 16.0 to 30.8 respectively, even though a longer clinical day had only 2.5 hours more than a shorter day.

Patient teaching/discharge teaching, insulin administration, dressing change, oral medication administration, and subcutaneous or intramuscular injections did not show significant differences between shorter and longer clinical days (Table 1). Receiving a new admission, linen change, observing a specific procedure, and bed bath/general hygiene were skills that were also recorded during the study; they indicated no differences between shorter and longer days (Table 1).

Next, per hour frequencies were calculated to examine if higher frequencies in longer days were resulted simply from more hours to perform these skills. Per hour frequencies of skills were calculated in the following manner. The average of the sum total frequencies of 40 students for each skill was divided by 6 for shorter days and 8.5 for longer days. As shown in Table 1, the average per hour frequency of glucometer use was 2.2 times in shorter days and 3.6 times in longer days. Per hour PA frequency showed 3.2 in shorter days and 4.7 in longer days. Per hour frequencies of the following skills showed slightly less frequent in longer days than shorter days: Passing trays, Receiving a new admission, Linen change, Observing a special procedure, and Bed bath/General hygiene (Table 1). 


\begin{tabular}{|l|l|l|l|l|l|}
\hline Skills performed & $\begin{array}{l}\text { Means in a Short } \\
\text { Day (+SD) }\end{array}$ & $\begin{array}{l}\text { Means in a Long } \\
\text { Day (+SD) }\end{array}$ & $\begin{array}{l}\text { T test } \\
\mathrm{P}=\end{array}$ & \multicolumn{2}{l|}{ Per hour frequencies } \\
\cline { 4 - 6 } & $13.3(+5.9)$ & $30.8(+5.1)$ & 0.014 & Short & Long \\
\hline Glucometer for blood glucose & $19.3(+7.4)$ & $40.2(+8.9)$ & 0.015 & 2.2 & 3.6 \\
\hline Physical assessment & $16.0(+6.2)$ & $30.8(+10.1)$ & 0.043 & 3.2 & 4.7 \\
\hline Intake and output assessment & $11.0(+6.2)$ & $22.8(+5.5)$ & 0.056 & 2.7 & 3.6 \\
\hline Patient teaching / discharge teaching & $5.7(+3.2)$ & $11.2(+3.6)$ & 0.076 & 1.8 & 2.7 \\
\hline Insulin administration & $8.3(+3.5)$ & $13.8(+2.7)$ & 0.092 & 1.0 & 1.3 \\
\hline Dressing change & $13.7(+5.5)$ & $20.8(+3.2)$ & 0.139 & 1.4 & 1.6 \\
\hline Oral medication administration & $5.0(+4.4)$ & $10.6(+3.8)$ & 0.142 & 2.3 & 2.4 \\
\hline Subcutaneous or IM & $22.0(+0.0)$ & $26.2(+8.2)$ & 0.317 & 0.8 & 1.2 \\
\hline Passing trays & $2.7(+1.5)$ & $3.0(+1.4)$ & 0.774 & 3.7 & 3.1 \\
\hline Receiving a new admission & $15.7(+5.8)$ & $16.0(+4.4)$ & 0.936 & 0.5 & 0.4 \\
\hline Linen change & $13.0(+3.0)$ & $13.2(+6.5)$ & 0.955 & 2.6 & 1.9 \\
\hline Observing a special procedure & $17.0(+6.2)$ & $17.2(+5.4)$ & 0.965 & 2.2 & 1.6 \\
\hline Bed bath/general hygiene & & 2.8 & 2.0 \\
\hline
\end{tabular}

Table 1. Comparison of the mean frequencies of nursing skills performed by 40 novice NSs in a short clinical day with a long clinical day.

On the last clinical day, students were asked to describe the perceived benefits of shorter clinical days as compared to longer clinical days. As for perceived benefits from two shorter clinical days per week, five students stated that the shorter days were "busy" which promoted better understanding of prioritization of care $(13 \%$ of NSs), four students stated learning from various nurses $(10 \%)$, six students described being better able to follow up on the patients on the second clinical day (15\%), three students reported they had a more comprehensive understanding of the patient diagnoses $(8 \%)$, and three students recounted able to develop an enhanced relationship with patients on the second consecutive day ( $8 \%)$.

As for perceived benefits of longer clinical days, the majority of the students stated more opportunities to practice various skills and observing procedures $(85 \%)$, and ten students stated the opportunity to repeat PA and recognize the progress of the patients over time $(25 \%)$. Eleven students commented on the ability to build relationship with the patient and family $(28 \%)$. Five students identified more opportunity to build professional relationship with the staff nurse (13\%). Three students stated better understanding of pathophysiology of disease ( $8 \%$ ). Two students reported being better able to provide "holistic care" (5\%). Additionally, students reported less feelings of anxiety (one student), less stress (one student) and more confidence (one student) in their role as a NS.

\section{Discussions and Conclusions}

The NSs' first clinical rotation of our BSN program in the Fall semester of 2016 was developed as an inaugural mixed clinical course. This entailed two shorter clinical days per week in conjunction with one longer clinical day per week. To evaluate the new clinical schedule for novice NSs with the mixed length of clinical days, a study was conducted to investigate the differences in the skills frequency between a shorter day and a longer day. Additionally, data on student perceptions of benefits of shorter and longer clinical days in one rotation were collected for analysis.

As expected, the results showed that more skills were performed in longer clinical days. Moreover, although a longer day consisted only a 2.5 hours more than a shorter day (6 hours vs. 8.5 hours), novice NSs performed skills such as PA, glucometer use, and I/O assessment twice as often in longer days. There was also a trend of more frequent performances in other skills in a longer clinical day. Per hour frequency analyses confirmed that the increase in frequencies of performing these skills was not due to more hours in longer clinical days.

Per hour frequency analyses also indicated that novice NSs performed linen change, passing trays and bed-bath hygiene less frequently in longer days which were the latter half of the semester. These skills were commonly performed during the morning hours, thus per hour frequencies of these skills in longer clinical days may have resulted in reduced numbers. The reduced frequencies of these skills may also suggest that novice NSs prioritized to perform more technical skills than skills required for basic care as they learned more complex skills in the latter semester. It is recommended to remind novice NSs the importance of providing basic care for their assigned patients as well as performing newly learned skills.

Novice NSs also developed stronger relationships with the nursing staff, patients and their family members during the longer days, whereas on the shorter clinical day the NSs focused primarily on skill performance. This, however, may have been due to the fact that the shorter clinical days were at the beginning of the first clinical rotation, when the NSs' skills, knowledge and experiences were limited. The thread to the external validity of maturation must be acknowledged in the interpretation of the results. In addition, the NS's limited clinical experience and high levels of anxiety at the beginning of the rotation may have prevented them from developing effective relationships with patients and staff nurses during the shorter clinical days. The report by novice NSs of having a decreased fear and anxiety on the second consecutive day may indicate the importance of having two shorter clinical days per week at the beginning of the first rotation.

\section{Limitations and Recommendations}

Clinical learning outcomes of NSs may not solely depend on the length of clinical hours but may depend on how clinical education is conducted $(1,2)$. As discussed above, the students' maturation may have affected the results, with more skills practiced in a longer clinical days in this study. The recommended design for future studies to control the threat to the external validity of maturation may be a 
longitudinal comparative design of two cohorts: (A) novice NSs with two shorter days per week and (B) novice NSs with one longer days per week throughout the first clinical semester. Nonetheless, a mixedlength clinical practice with shorter days at the beginning, and longer days thereafter during the first clinical semester is recommended by many novice NSs in this study, as well as by clinical faculty members. A mixed clinical schedule may bring better learning outcomes, as novice NSs gain more experience and knowledge with reduced anxiety over time during the first clinical rotation.

\section{References}

1. Rosenberg, K. (2015). Short and long clinical learning days yield equal results. Am J Nurs 115: 57.

2. Danner, $\mathrm{M}$ (2014) Comparison of 1 long versus 2 shorter clinical days on clinical learning outcomes of NSs. Nurse Educator, 39(6), 280-284.

3. Tobar K, Wall D, Parsh B, Sampson J (2007) Use of 12-hour clinical shifts in nursing education: Faculty, staff, and student response. Nurse Educator, 32(5), 190-191.

4. Rossen B, Fegan M (2009) Quick reads. Eight- or twelvehour shifts: what NSs prefer. Nursing Education Perspectives (National League For Nursing) 30: 40-43.

5. Gignac DA, Walker GM (1994) Extended shifts for nursing students? Nurse Educator, 19: 7.

6. Reising DL, Fickenscher R, Satrom A (2017) Comparison of differing clinical schedules for NSs. Nurse Educator 42: 8-13.

7. Heaslip J (1988) Student reaction to the 12-hour shift in an undergraduate baccalaureate nursing program. Journal Of Nursing Education, 27(1), 19-22.

8. Wallace L, Bourke MP, Tormoehlen LJ, Poe-Greskamp MV (2015) Perceptions of clinical stress in baccalaureate NSs. Int J Nurs Edu Scholarship 12: 1-8.

9. Reid N, Robinson G, Todd C (1994) The 12-hour shift: the views of nurse educators and students. Journal Of Advanced Nursing 19: 938-946.

10. Bayoumi MMM, Elbasuny MMM, Mofereh AM, Assiri, MAM, Al Fesal AH et al. (2012) Evaluating nursing students' anxiety and depression during initial clinical experience. Int J Psychol Behav Sci 2: 277-281.

11. Sun F, Long A, Tseng YS, Huang H, You J (2016) Undergraduate student nurses' lived experiences of anxiety during their first clinical practicum: A phenomenological study. Nurse Education Today 37: 21-26. 